Modelagem geoestatística dos casos de dengue e da variação termopluviométrica em João Pessoa, Brasil Alexandro Medeiros Silva, Richarde Marques da Silva, Caio Américo Pereira de Almeida , José Jeferson da Silva Chaves

\title{
MODELAGEM GEOESTATÍSTICA DOS CASOS DE DENGUE E DA VARIAÇÃO TERMOPLUVIOMÉTRICA EM JOÃO PESSOA, BRASIL
}

\section{Geostatistical modeling of dengue fever and temperature-rainfall variation in João Pessoa, Brazil}

Alexandro Medeiros Silva

Universidade Federal da Paraíba, João Pessoa, Paraíba, Brasil medeiros_alexandro@hotmail.com

Richarde Marques da Silva Universidade Federal da Paraíba, João Pessoa, Paraíba, Brasil richarde.marques@gmail.com

Caio Américo Pereira de Almeida Universidade Federal da Paraíba, João Pessoa, Paraíba, Brasil caioamerico@gmail.com

José Jeferson da Silva Chaves Universidade Federal da Paraíba, João Pessoa, Paraíba, Brasil jeferson_jampa@hotmail.com

Artigo recebido em 19/04/2013 e aceito para publicação em 11/03/2015

RESUMO: A dengue é uma doença viral cujo número de casos aumentou consideravelmente nas últimas décadas em várias regiões do Brasil. Este estudo teve como objetivo investigar os fatores climáticos associados aos de casos da dengue na cidade de João Pessoa, Paraíba, no período de 2007 a 2011. Os dados termopluviométricos foram coletados junto ao INMET, e os casos de dengue foram obtidos na Secretaria de Saúde do Município de João Pessoa. No total foram notificados 9.467 casos confirmados de dengue, assim distribuídos: 33,2\% no ano de 2007, 8,8\% em 2008, 2,6\% em 2009, 12,4\% em 2010, e 42,9\% em 2011. As maiores ocorrências de casos de dengue ocorram na porção sul do município. Verificou-se que a precipitação e a umidade relativa do ar são as variáveis climáticas que mais favorecem a ocorrência de dengue.

Palavras-chave: SIG. Geografia da Saúde. Espaço urbano.

ABSTRACT: Dengue is a viral disease whose incidence has increased considerably in recent decades. This study aimed to investigate the climatic factors associated with the incidence of dengue fever in the city of João Pessoa, Paraíba State, in the period between 2007 and 2011. The analysis has included thermo-rainfall collected in INMET, and the cases of dengue obtained in the Health Department of the municipality. In total were reported 9,467 confirmed cases of dengue, as follows: $33.2 \%$ in $2007,8.8 \%$ in $2008,2.6 \%$ in $2009,12.4 \%$ in 2010, and $42.9 \%$ in 2011. The highest incidences of dengue cases occur in the south part of the city. It was found by correlating time-lag that rainfall and relative humidity are the climatic variables that favor the occurrence of dengue in João Pessoa.

Keywords: GIS. Health Geography. Urban space.

DOI: http://dx.doi.org/10.1590/1982-451320150111 


\section{INTRODUÇ̃̃O}

Estudar a variabilidade de variáveis climatológicas é atualmente um desafio para diversas áreas do conhecimento, sobretudo devido à grande relevância sobre as implicações da disponibilidade hídrica em ambientes rurais e urbanos (SILVA et al., 2010). O clima é considerado como o elemento condicionador da dinâmica do meio ambiente, pois exerce influência direta tanto nos processos de ordem física quanto biológica, assim como na sociedade de modo geral, constituindo-se, portanto, em um recurso essencial para a vida e para as atividades humanas.

O estudo do comportamento espacial de variáveis climáticas, como é o caso da precipitação, umidade relativa do ar e temperatura é fundamental, tanto para o gerenciamento dos recursos hídricos quanto para o planejamento das atividades urbanas. A identificação de regiões homogêneas quanto aos padrões individual ou combinado de diferentes elementos meteorológicos tem sido uma prática habitual e desenvolvida por diferentes metodologias seja pelo uso de técnicas de análise multivariada ou por geoestatística, com o auxílio de Sistemas de Informações Geográficas.

Mais recentemente, as geotecnologias vêm sendo utilizadas para auxiliar no mapeamento das ocorrências de casos de doenças e na caracterização epidemiológica de endemias. Diversas metodologias têm sido utilizadas na formulação de estratégias de controle de diversas doenças (FLAUZINO et al., 2009; CARVALHO e NASCIMENTO, 2012; HASSAN et al., 2012). O uso de metodologias que melhor destacam a influência dos processos ambientais e sociais nos padrões de transmissão de doenças são de extrema valia para adoção de medidas mitigadoras para prevenção e controle de doenças. Dessa forma, a modelagem espacial da relação entre a variação termopluviométrica e os registros dos casos de dengue em uma determinada região constitui importante instrumento de apoio ao planejamento e ações contra a proliferação da doença no espaço urbano.

A série histórica de incidências de dengue no Brasil revela tendência ascendente da transmissão da doença, com valor máximo no ano de 2002
(MONDINI et al., 2005). Atualmente, a doença está presente em 25 dos 27 estados brasileiros, e o mosquito vetor, em todos eles. As curvas de transmissão dessa doença no Brasil apresentaram comportamento cíclico, intercalando anos com incidências mais altas e anos com incidências mais baixas (MINISTÉRIO DA SAÚDE, 2002). Essa tendência de aumento dos casos de dengue e dengue hemorrágico tem ocorrido, apesar dos esforços realizados em termos de medidas de controle. Para Khormi e Kumar (2012), as razões para tal situação são complexas e não totalmente compreendidas, sendo necessária a realização de estudos mais aprofundados para sua elucidação.

Segundo Mondini et al. (2009) e Khormi et al. (2011), muitos fatores de risco estão associados à presença da doença e do vetor, dentre eles o crescimento populacional, urbanização inadequada, migrações, problemas de infraestrutura das cidades, falta de maior conscientização da população, viagens aéreas e deterioração dos sistemas de saúde. Para Gómez-Dantés (1995), a densidade da população é um fator importante para definir o padrão de transmissão de doenças, pois, tanto em cidades médias quanto grandes há uma maior probabilidade de que ocorram a infestação e a transmissão de doenças. Além disso, o controle de doenças nesses locais é difícil devido ao fato da limitação de recursos, à grande extensão e à heterogeneidade do espaço urbano (BARRERA et al., 2000).

Nessa perspectiva, o uso das geotecnologias tornou-se fundamental para aplicação na área de saúde, com destaque para análises da distribuição espacial de endemias (SILVA et al., 2012a). Sendo assim, a abordagem espacial, através de softwares especializados, permite a integração de dados demográficos, econômicos e ambientais, promovendo o inter-relacionamento das informações de diversos bancos de dados (KHORMI et al., 2011).

Segundo Sá et al. (2009), a aplicabilidade de Sistemas de Informação Geográfica (SIGs) contribui no controle e no monitoramento de doenças, auxilia medidas de profilaxia mais adequadas, possibilita uma avaliação constante das medidas de controle empregadas e fornece informações atualizadas da real situação epidemiológica no espaço geográfico, devido à integração e armazenamento de dados 
existentes conjuntamente com a análise espacial (SILVA et al., 2012b).

Conhecidamente, o maior número de casos de dengue no mundo ocorre em regiões tropicais, devido ao fato das grandes variações de precipitação, temperatura e umidade do ar durante o ano. Por isso, muitos estudos têm sido realizados envolvendo técnicas de SIG aplicadas à saúde, como Barcellos et al. (2005) no Brasil, Tipayamongkholgul e Lisakulruk (2011) na Tailândia, Mena (2011) na Costa Rica, e Khormi et al. (2011) na Arábia Saudita. Face ao exposto, o conhecimento da relação espacial dos casos de dengue pode propiciar maior entendimento sobre a dinâmica de transmissão e seu controle (RIBEIRO et al., 2006), tendo em vista as adaptações do mosquito transmissor da dengue aos fatores abióticos. Assim, este trabalho analisou a relação das variações climáticas sazonais na distribuição geográfica dos casos de dengue no município de João Pessoa no período compreendido entre 1970 e 2011.

\section{MATERIAIS E MÉTODOS}

\section{A área de estudo}

O Município de João Pessoa possui uma área de aproximadamente $212 \mathrm{~km}^{2}$, com uma população total de 723.515 habitantes e uma densidade demográfica de $3.421,30 \mathrm{hab} / \mathrm{km}^{2}$, segundo o Censo Populacional de 2010 (IBGE, 2010). João Pessoa está localizado na porção litorânea do Estado da Paraíba, entre os municípios de Cabedelo, Conde, Bayeux e Santa Rita, mais precisamente entre as coordenadas $283500 \mathrm{mE}$ e $303000 \mathrm{mE}$ e $9198000 \mathrm{mN}$ e 9220000 $\mathrm{mN}$, Fuso 25 (Figura 1).

Figura 1. Localização geográfica do município de João Pessoa-PB.
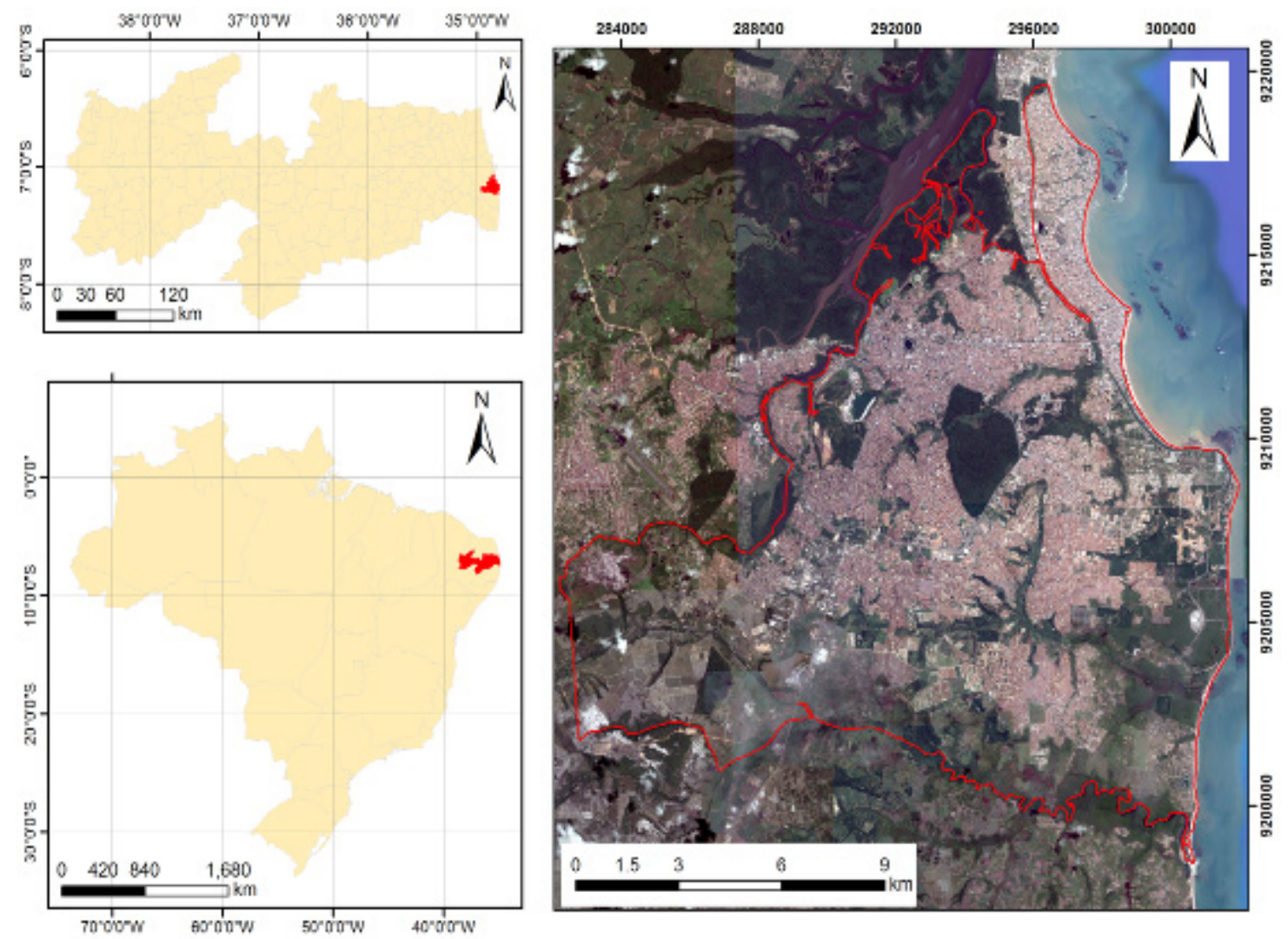

Fonte: Pesquisa direta. Org. dos autores. 
A cidade de João Pessoa situa-se no Litoral do Estado da Paraíba, na Mesorregião da Zona da Mata, no baixo planalto costeiro, sobre uma formação sedimentar proveniente de acumulações do próprio continente, nesse caso de materiais desagregados do Planalto da Borborema, fazendo parte do Grupo Barreiras. Possui clima quente e úmido do tipo Intertropical, com temperaturas médias anuais em torno de $25^{\circ}$ a $26^{\circ} \mathrm{C}$. As estações são bem definidas com inverno de Março até Agosto e nos outros meses predomina-se o Verão. A média anual da umidade relativa do ar é de aproximadamente $80 \%$. A precipitação anual é em torno de $1.900 \mathrm{~mm} / \mathrm{ano}$, e a temperatura máxima é de $29,6^{\circ} \mathrm{C}$.

\section{Construção da base de dados}

Os dados utilizados neste estudo foram obtidos junto à Secretaria Municipal de Saúde do Município de João Pessoa, referente aos casos registrados de dengue entre 2007 e 2011. Para a construção da base cartográfica foi utilizada uma imagem de alta resolução espacial do satélite Quickbird de 2011. Essa imagem foi georreferenciada e em seguida foram traçadas as ruas, os limites dos bairros, a malha quadras de lotes e do município de João Pessoa.

Os atributos dos casos detectados de dengue foram: endereço completo (rua, número, CEP e bairro), o posto de saúde de origem, sexo, idade, número de residentes no mesmo domicílio e estado civil. Os casos notificados da doença foram geocodificados com base no endereço contido na ficha de atendimento do paciente. Cada caso foi localizado geograficamente a partir da localização do endereço da residência do paciente na base cartográfica da malha de lotes do município de João Pessoa.

Entretanto, muitos dos casos não foram localizados devido a falhas no preenchimento dos formulários referentes ao endereço dos pacientes, pois, algumas informações estavam incompletas, como por exemplo, o endereço completo da residência, o que impossibilitou a localização geográfica de alguns dos casos notificados.

No que tange a base de dados termopluviométricos, foram utilizados dados diários da estação meteorológica de João Pessoa, para o período de 1970 a 2011, das variáveis: (a) precipitação, (b) umidade relativa do ar, e (c) temperatura máxima. Esses dados foram obtidos junto ao Instituto Nacional de Meteorologia (INMET), acessando o banco de dados climático no endereço: $\mathrm{http} / / / \mathrm{www}$. inmet.gov.br/portal.

\section{Modelagem Geoestatística: Análise Espacial dos Casos de Dengue}

A análise espacial tem como ênfase mensurar propriedades e relacionamentos, levando-se em consideração a localização geográfica do fenômeno em estudo de forma explícita. A análise espacial pode ser definida como uma técnica que busca descrever os padrões existentes nos dados espaciais e estabelecer, preferencialmente de forma quantitativa, os relacionamentos entre as diferentes variáveis geográficas.

Segundo Câmara e Carvalho (2011), essa técnica compreende três métodos: métodos de visualização; métodos exploratórios e métodos que auxiliem a escolha de um modelo estatístico e a estimação dos parâmetros desse modelo. Esses métodos utilizam os seguintes procedimentos: (a) seleção, (b) manipulação, (c) análise exploratória, e (d) modelagem espacial, utilizando o programa Spring 5.2.2.

Para se analisar a espacialização dos casos e dengue foi utilizado o estimador de intensidade Kernel. O estimador de intensidade Kernel é uma técnica exploratória para analisar o comportamento de pontos e estimar a intensidade pontual do processo em toda a região de estudo. Essa função realiza uma contagem de todos os pontos dentro de uma região de influência, ponderando-os pela distância de cada um a localização de interesse, como mostrado na Figura 2 .

Soc. \& Nat., Uberlândia, 27 (1): 157-169, jan/abr/2015 
Figura 2. Caracterização do estimador de intensidade Kernel

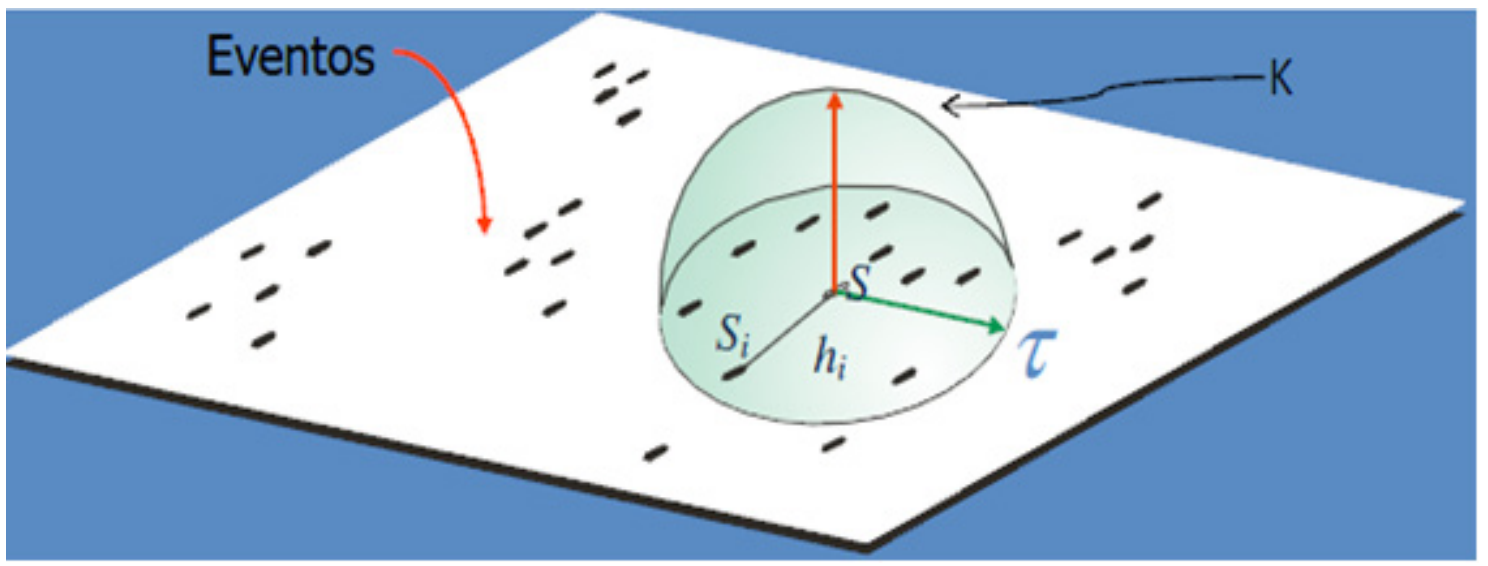

Fonte: Câmara e Carvalho (2011).

Assim, pode-se ajustar uma função bidimensional sobre os eventos considerados, compondo uma superfície cujo valor será proporcional à intensidade de amostras por unidade de área. Para obter o mapa das áreas de risco do município de João Pessoa, optou-se pelo estimador de intensidade Kernel, por este ser um método muito útil, de fácil uso e interpretação para o conhecimento da distribuição de eventos de primeira ordem.

O estimador Kernel é um método não paramétrico para estimação de curvas de densidades, onde cada observação é ponderada pela distância em relação a um valor central, o núcleo. Esse estimador realiza uma contagem de todos os pontos dentro de uma região de influência, ponderando-os pela distância de cada um em relação à localização de interesse.

Este estimador não é contínuo e depende fortemente da escolha do raio da distância $(h)$, conhecido como parâmetro de suavização. Assim, variando o valor de $h$ obtemos diferentes formas de $f(x)$. O estimador Kernel é dado por:

$$
f(\mathrm{x})=\frac{1}{n} \sum_{\mathrm{i}=1}^{n} \frac{1}{\tau} \mathrm{K}\left(\frac{s-S_{i}}{\tau}\right)
$$

Sendo $f(x)$ a função de intensidade, $\tau$ o raio de influência $(\tau \geq 0)$ que define a vizinhança do ponto a ser interpolado que controla o "alisamento" da superfície gerada, K é uma função de interpolação do Kernel, $s$ é o centro da célula a ser estimada, e $S_{i}$ é o local do ponto que coincide com o centróide das áreas dentro do raio.

A escolha do raio de influência é crucial, pois com um raio muito grande a superfície parecerá plana, amaciada, desse modo às características locais serão ocultadas, enquanto que para um raio pequeno a superfície tenderá a picos centrados gerando uma superfície muito descontinua.

O raio de influência define a área central no ponto de estimação $u$ que indica quantos eventos $u_{i}$ contribuem para a estimativa da função intensidade $\lambda$. Um raio muito pequeno irá gerar uma superfície muito descontínua; se for grande demais, a superfície poderá ficar muito suavizada, o resultado pode sugerir uma homogeneidade na região. Já $h$ representa a distância entre a localização em que desejamos calcular a função e o evento observado. Após a montagem do banco de dados aplicou-se o estimador Kernel com tamanho da célula de saída de $50 \mathrm{~m}$ e raio de $1000 \mathrm{~m}$, para avaliar a ocorrência dos casos de dengue.

\section{Procedimentos éticos}

Este trabalho foi conduzido dentro dos padrões exigidos pela Declaração de Helsinque e da Resolução 196/1996, do Conselho Nacional de Saúde (BRASIL, 1996). Para a realização do referido estudo, o estudo foi previamente submetido à apreciação do Comitê de Ética em Pesquisa do Centro de Ciências da Saúde, da Universidade Federal da Paraíba. 
Como este trabalho utilizou apenas o banco de dados da Secretaria da Saúde foi solicitada a dispensa do Termo de Consentimento Livre e Esclarecido, porém, foi garantido o sigilo das informações.

\section{RESULTADOS E DISCUSSÕES}

A Figura 3 apresenta a variabilidade anual da precipitação pluvial média no município de João
Pessoa entre 1970 a 2011 (Média anual: $1.850 \mathrm{~mm}$; Desvio médio: $532 \mathrm{~mm}$; Desvio padrão: $637 \mathrm{~mm}$ ). Pode-se observar a variabilidade nesta série, com destaque para o valor da precipitação máxima anual próxima de $2.000 \mathrm{~mm}$. Percebe-se que em alguns anos ocorreram precipitações significativamente muito acima da média, como em 1970, 1973,1985, 1994 e 2009 (acima de $2.500 \mathrm{~mm}$ ).

Figura 3. Evolução anual da precipitação média para o município de João Pessoa no período de 1970 a 2011.

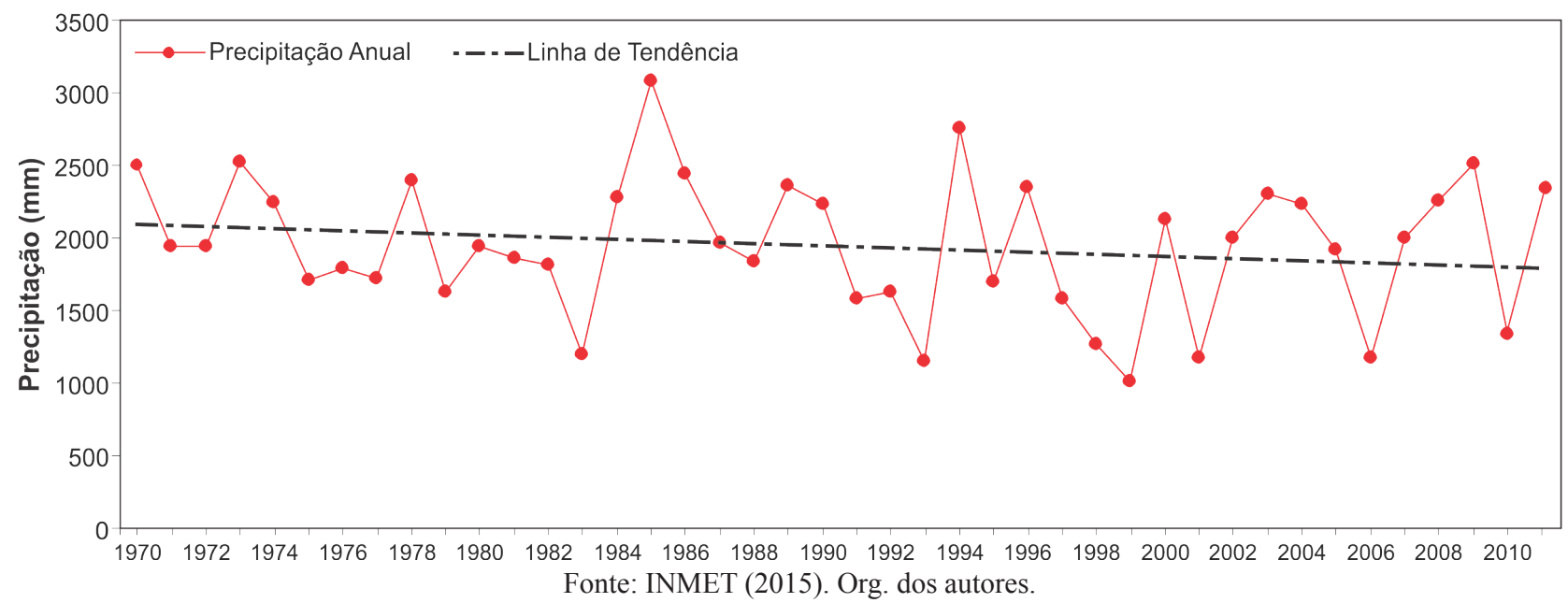

Para as séries pluviométricas mínimas, ou seja, abaixo da média foram registradas em torno de 500 a $1.000 \mathrm{~mm}$, com destaque para os anos de 1975, 1979, 1980 e 1981. Segundo Andreoli e Kayano (2007) e Silva et al. (2010) essas anomalias são influenciadas pela variabilidade anual e interanual que são características da região Nordeste do Brasil, que sofrem a influência dos eventos El Niño e La Niña.

Na Figura 4, pode-se observar a variabilidade pluvial anual em João Pessoa com relação às anomalias. Dentro do período estudado, 13 anos tiveram precipitação pluvial acima da média, dos quais seis destes anos registraram um aumento superior a $200 \mathrm{~mm}$ de precipitação média anual em relação à média histórica do município. Nota-se que no período estudado, 17 anos registraram precipitação anual abaixo da média histórica do município. 
Figura 4. Anomalia das precipitações médias anuais (mm), para o período de 1970 a 2011 em João Pessoa.

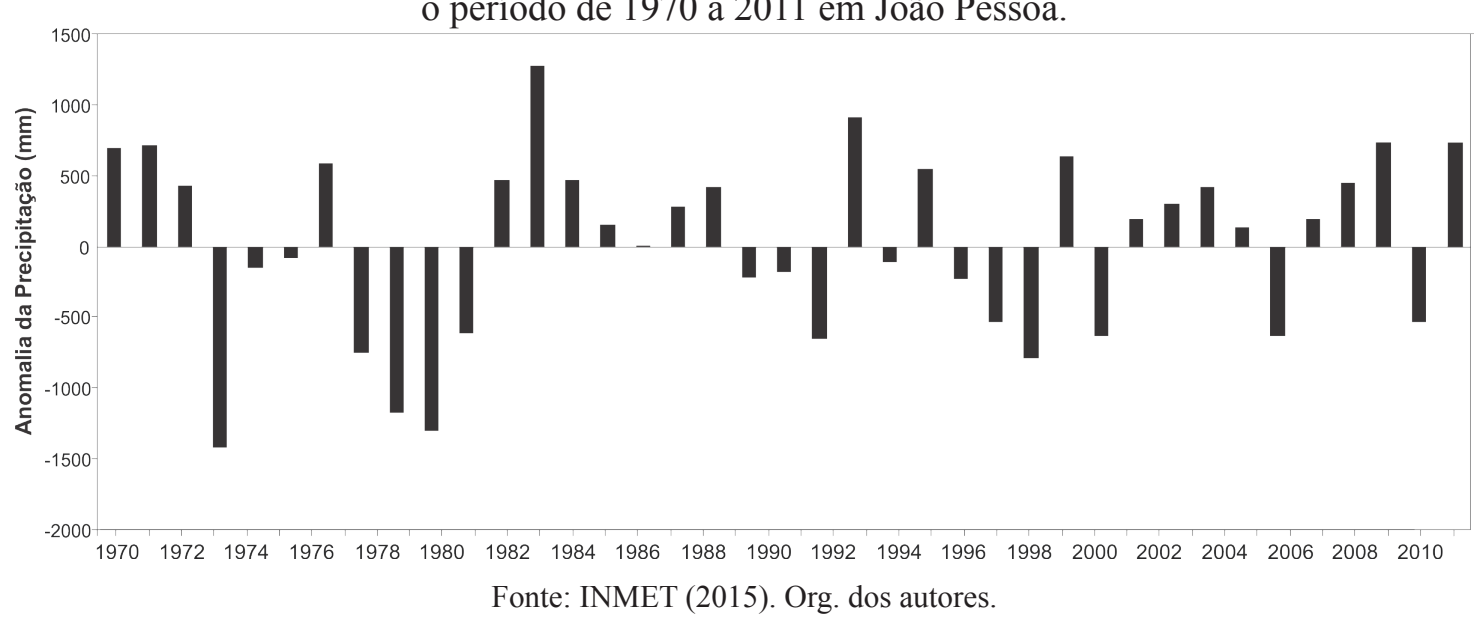

A Figura 5 (atentar para as variáveis termopluviométricas $5 \mathrm{a}-5 \mathrm{c}$ ) apresenta a variação mensal das variáveis termopluviométricas analisadas neste estudo e a quantidade de casos de dengue em João Pessoa. Percebe-se que a maior quantidade de caos ocorre no período entre os meses de março a agosto, período no qual ocorrem os maiores valores de precipitação e umidade relativa do ar, e consequentemente, as temperaturas mais baixas registradas na região.

Figura 5. Comparação entre os casos de dengue em João Pessoa entre 2007 e 2011 e as variáveis termopluviométricas: (a) precipitação, (b) umidade relativa do ar, e (c) temperaturas máxima, mínima e média.
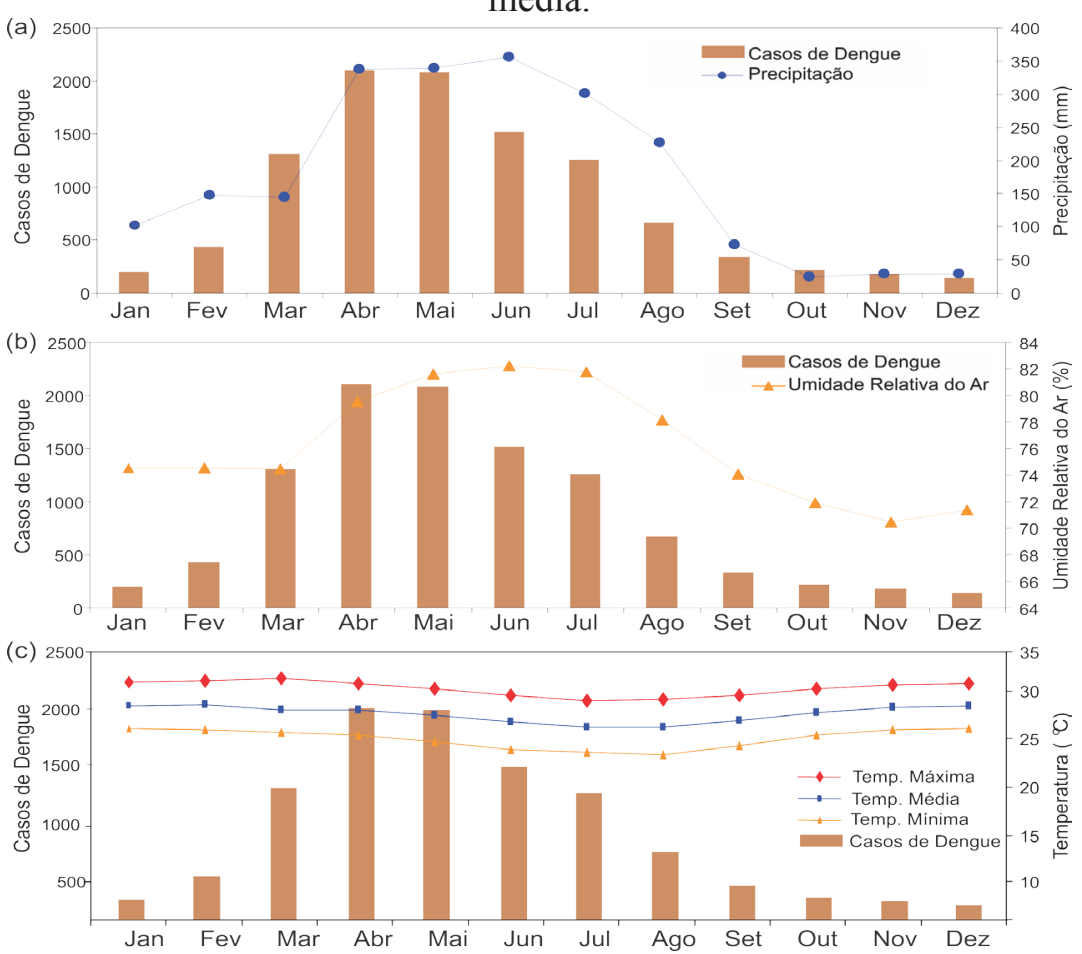

Fonte: Secretaria Municipal de Saúde do Município de João Pessoa e INMET (2015).

Org. dos autores. 
De acordo com os dados obtidos, o período chuvoso, que representa mais de $80 \%$ do total histórico de chuva no município foi responsável por concentrar um total de 8.949 casos da doença em todo o período estudado, ou seja, $85 \%$ do total de casos notificados. Isso mostra que o período chuvoso deve concentrar maior atenção dos órgãos municipais e estaduais no combate à doença, e intensificar também a participação da população na tomada de medidas mitigadoras contra os focos da doença. Deve-se ressaltar que o período de 2007 a 2011 foi marcado por valores de precipitação acima da média histórica da região. Esse fato contribui significativamente para a proliferação dos casos da doença na região, como evidenciado na Figura 6, pois a precipitação se mostrou a variável climática que mais influenciou nos casos de dengue.
A análise comparativa do período analisado em que se dividiu a série histórica das incidências mensais permitiu caracterizar o comportamento endêmico do dengue, o processo comumente denominado endemização pelos órgãos de controle. $\mathrm{O}$ termo não se refere apenas à constatação de que a doença é um fato esperado no município, e não se trata mais de epidemia, mas também à generalização da transmissão por todos os meses do ano. Não há mais a necessidade de introdutores para a continuidade da transmissão no município. É evidente que casos importados necessitam de vigilância e são importantes fontes de infecção, mas a transmissão ocorre independente deles.

Figura 6. Relação entre os casos de dengue e a precipitação mensal em João Pessoa entre 2007.

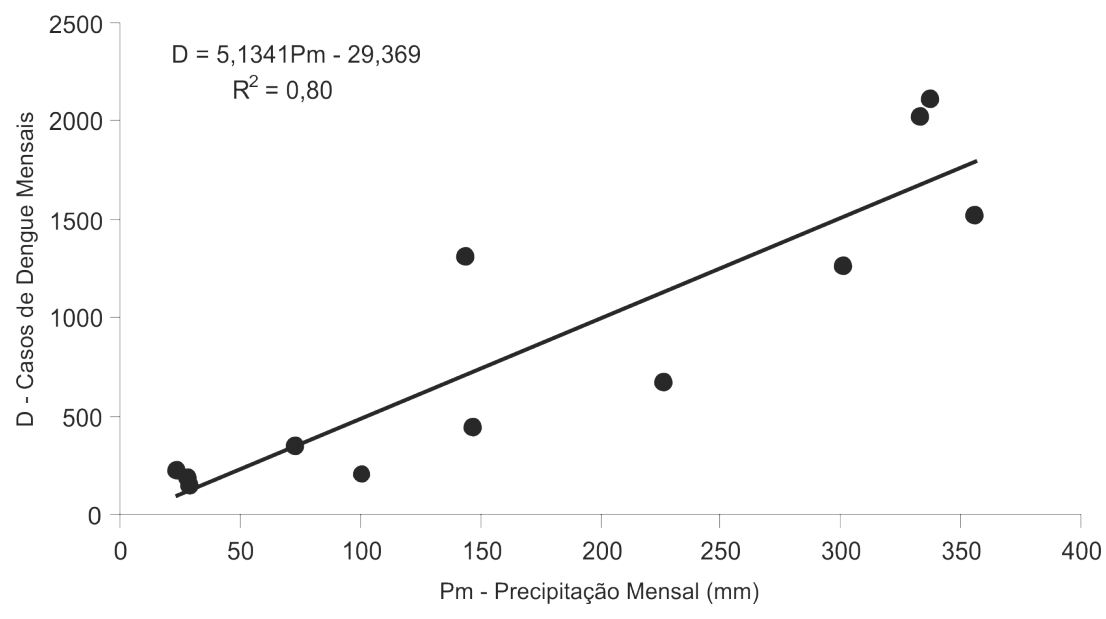

Fonte: Secretaria Municipal de Saúde do Município de João Pessoa e INMET (2015).

Org. dos autores.

A dengue vem demonstrando um rápido crescimento no número de casos e uma importante expansão espacial sobre o município de João Pessoa, desde a confirmação dos primeiros casos autóctones em 2003. Paralelo a esta expansão da doença, observou-se na última década importantes variações climáticas nas médias térmicas e na distribuição das precipitações. Entre 2007 e 2011, confirmou-se aquecimento em todas as estações do ano, destacandose o inverno, cuja média do período superou em $0,6^{\circ} \mathrm{C}$ a média histórica.
A Figura 7 (atentar para $7 \mathrm{a}-7 \mathrm{e}$ ) mostra a localização geográfica dos casos de dengue notificados em João Pessoa entre os anos de 2007 e 2011. A Figura 7 (atentar para 7f) apresenta ainda a inserção de todas as ocorrências da doença na base cartográfica no período estudado.

A investigação da distribuição de casos em cada bairro da cidade indicou que no primeiro ano epidêmico (2007), os bairros que concentraram maior número de casos estavam situados na porção sudeste e noroeste da cidade. No segundo e terceiro 
ano de epidemia (2008 e 2009) houve uma sensível redução na quantidade dos casos da doença, e notase uma menor concentração da doença na porção sul da cidade. Essa configuração espacial da doença não foi retratada em 2010 e 2011, onde se percebe um aumento no número de casos da doença.

Os bairros com maior número de casos situam-se na porção sudeste e noroeste da cidade, as duas áreas que concentram a maior parte da população de João Pessoa, onde se situam os bairros Mangabeira, José Américo e Geisel (porção sudeste) e Mandacaru (porção noroeste). Um dos objetivos da análise de padrões pontuais é verificar se os eventos avaliados apresentam comportamento sistemático como agrupamento ou irregularidade.

Figura 7. Distribuição espacial dos casos de dengue em João Pessoa em: (a) 2007, (b) 2008, (c) 2009, (d) 2010, (e) 2011, e (f) total de casos em todos os anos.
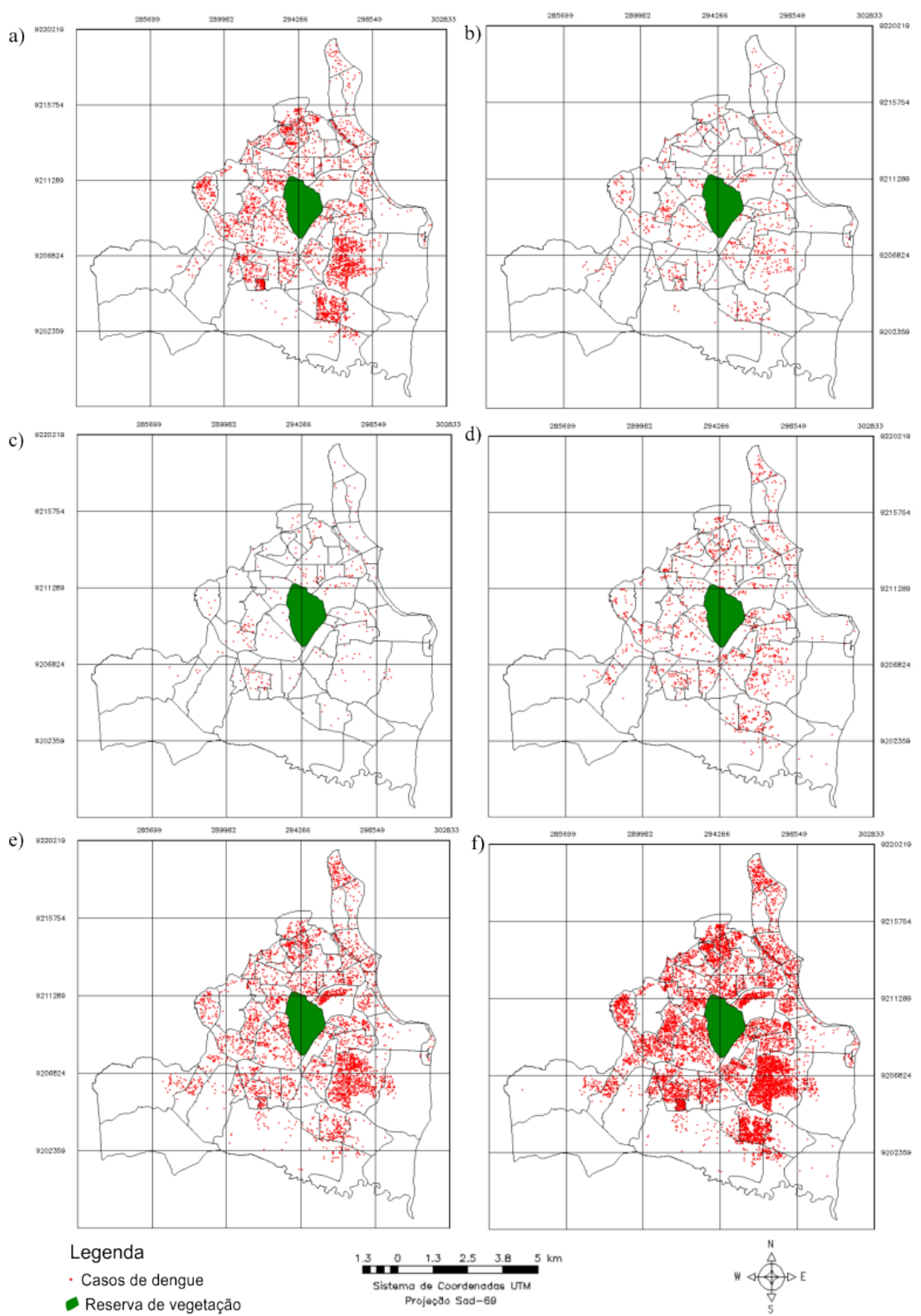

- Reserva de vegetação

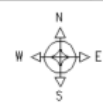

Fonte: Secretaria Municipal de Saúde do Município de João Pessoa. Org. dos autores. 
Para se analisar a intensidade dos casos de dengue ocorridos numa mesma residência, isto é, dois ou mais casos notificados da doença utilizou-se o estimador Kernel. A Figura 8 (atentar para 8a-8e) apresenta a distribuição de intensidade dos casos de dengue para cada ano estudado utilizando o estimador de Kernel. A distribuição de intensidade do total de casos da doença pode também ser visualizada pela Figura 8 (atentar para 8f).

Figura 8. Estimativa de Kernel da distribuição dos casos de dengue segundo os anos em João Pessoa em: (a) 2007, (b) 2008, (c) 2009, (d) 2010, (e) 2011, e (f) total de casos.
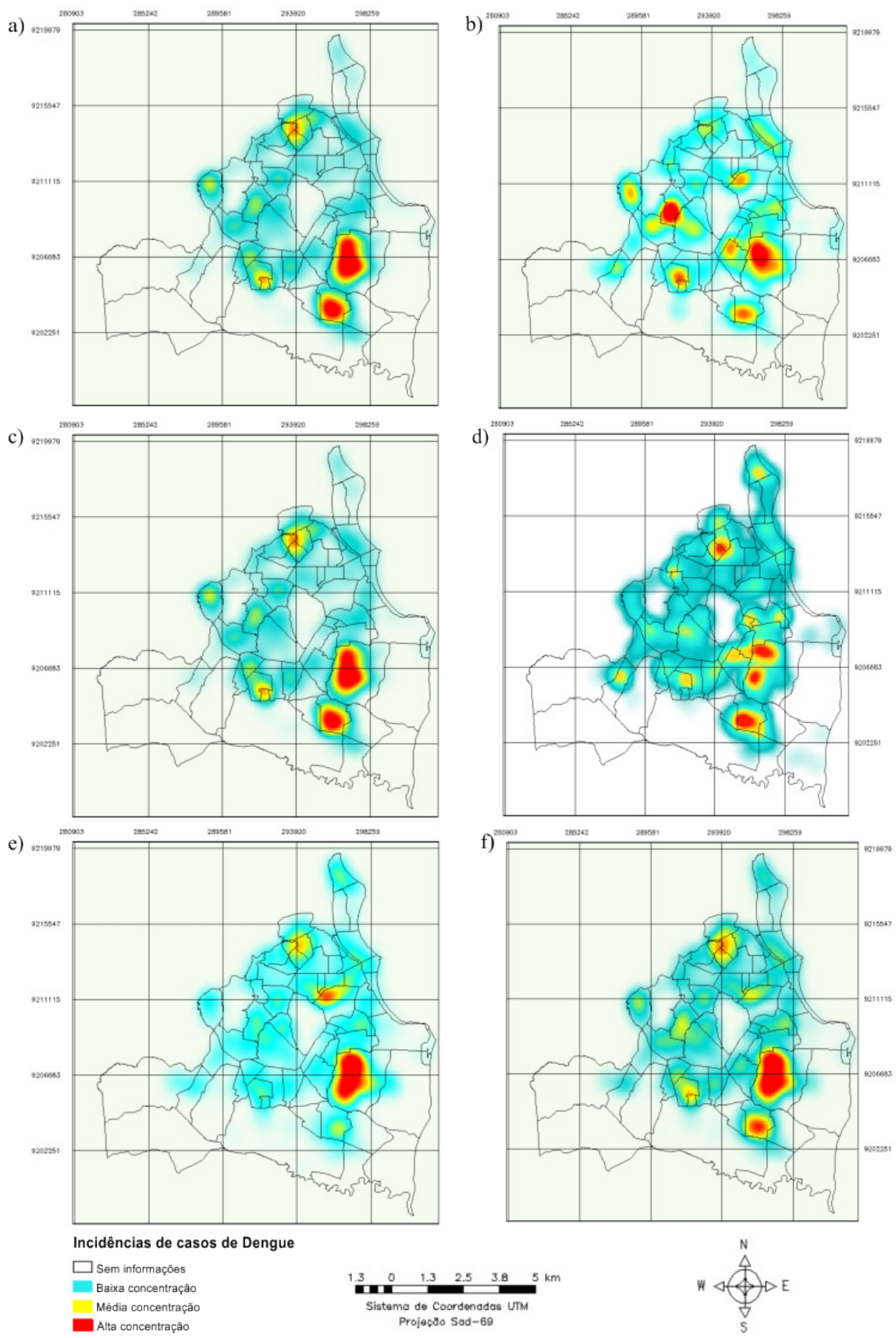

Fonte: Secretaria Municipal de Saúde do Município de João Pessoa. Org. dos autores. 
A estimativa de áreas sujeitas a uma maior ocorrência de riscos de casos de dengue através de Kernel revelou que há pelo menos três áreas que mais se destacam em todos os anos, nos bairros de Mangabeira, Valentina e Mandacaru/Roger, e destas a mais crítica é a situada no bairro de Mangabeira. Ainda em termos de distribuição, verifica-se que há uma menor concentração da doença nos bairros litorâneos e no bairro do Centro, que se caracterizam por uma maior concentração da população com melhores condições socioeconômicas e pela presença de atividades comerciais e de serviços.
A Figura 9 mostra a espacialização dos totais de casos de dengue em cinco classes, segundo os bairros de João Pessoa, destacando os nomes dos bairros com maior concentração da doença. Percebe-se que a doença foi mais presente na classe com mais de 770 casos, ocorrido em Mangabeira (19,3\%), 9 bairros com 272 a 769 casos $(33,4 \%)$, e 15 bairros com 136 a 271 casos $(27,3 \%)$, os demais registraram menos de 135 casos $(20,0 \%)$. Verificase que os bairros com menor incidência da doença estão localizados na zona litorânea na porção sudeste e também na porção sudoeste, devido ao fato dessas regiões serem menos populosas.

Figura 9. Total de casos de dengue segundo os bairros do município de João Pessoa entre 2007 e 2011.

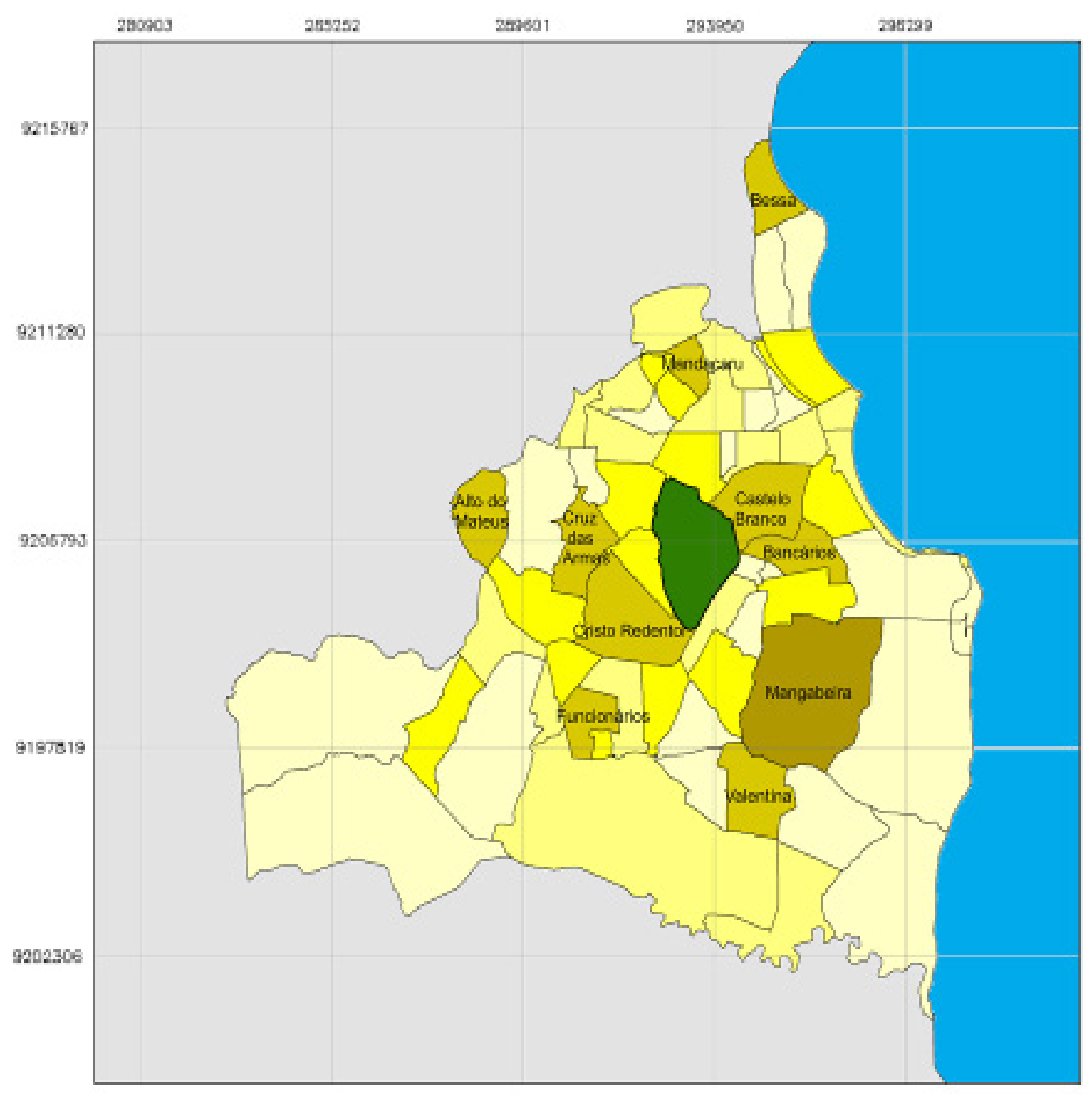

Fonte: Secretaria Municipal de Saúde do Município de João Pessoa. Org. dos autores. 
O primeiro questionamento a ser feito é se há possibilidade de atingir os objetivos propostos ao se utilizar as informações produzidas pelo sistema de vigilância e não por meio de inquéritos sorológicos especialmente desenhados para tal. As informações baseadas em casos notificados mostram apenas uma parte da realidade, pois é sabido que muitas pessoas infectadas ou são assintomáticas ou, mesmo que apresentem sintomas, não chegam a fazer parte das estatísticas oficiais (CHEN et al., 1996).

Dentro da perspectiva de que as ações de controle do dengue baseiam-se nas informações disponibilizadas pelo sistema de vigilância, a presente análise. Apesar de calcar-se apenas na parte visível do fenômeno, pode produzir conclusões, recomendações e hipóteses importantes, por ser a única ferramenta disponível no momento em que os casos ocorrem. Portanto, não se pretende compreender o processo de transmissão de forma completa, mas, entender causas e consequências da distribuição espacial dos casos de dengue em João Pessoa, e com isso aprimorar o sistema de controle da doença.

\section{CONCLUSÕES}

Este estudo abordou sobre a relação espaçotemporal da variação termopluviométrica e dos casos de dengue no Município de João Pessoa, Estado da Paraíba. Conclui-se do exposto que o uso de Sistemas de Informações Geográficas são ferramentas de grande valia para o estudo, análise e compreensão das relações entre os fenômenos termopluviométricos e os casos de doenças endêmicas, nesse caso a dengue, principalmente no tange a eficiência e praticidade no acompanhamento desses casos.

Face ao exposto, muitos dos principais fatores para a proliferação do vetor da doença ainda continuam acontecendo em ritmo acelerado, como o adensamento populacional e a urbanização, além dos fatores naturais, criando assim a necessidade de trabalhos por parte dos órgãos gestores, que previnam e conscientizem a população sobre a doença.

Novos estudos sobre essa problemática devem ser incentivados, visando assim uma melhor compreensão sobre a doença possibilitando um planejamento mais eficiente contra o referido problema. Além disso, esse trabalho serve de subsídio para futuras pesquisas sobre o mesmo tema ou em áreas afins.

\section{REFERÊNCIAS}

ANDREOLI, R. V.; KAYANO, M. T. A importância relativa do atlântico tropical sul e pacífico leste na variabilidade de precipitação do Nordeste do Brasil. Revista Brasileira de Meteorologia, v. 22, n. 1, p. 63-74, 2007. DOI: http://dx.doi.org/10.1590/S01027862007000100007

BARCELlOS, C.; PUSTAI, A. K.; WEBER, M. A.; BRITO, M. R. V. Identificação de locais com potencial de transmissão de dengue em Porto Alegre através de técnicas de geoprocessamento. Revista da Sociedade Brasileira de Medicina Tropical, v. 38, n. 3, p. 246-250, 2005. DOI: http://dx.doi.org/10.1590/ S0037-86822005000300008

BARRERA, R.; DELGADO, N.; JIMÉNEZ, M.; VILLALOBOS, I.; ROMERO, I. Estratificación de una ciudad hiperendémica en dengue hemorrágico. Revista Panamericana de Salud Publica, v.8, n.2, p.225-33, 2000. DOI: http://dx.doi.org/10.1590/ S1020-49892000000900001

BRASIL. Conselho Nacional de Saúde. Resolução $N^{o}$ 196 de 10 de outubro de 1996. Disponível em: <http:// dtr2004.saude.gov.br/susdeaz/legislacao/arquivo/ Resolucao_196_de_10_10_1996.pdf.> Acesso em: 06 de novembro de 2012.

CÂMARA, G.; CARVALHO, M. S. Análise espacial de eventos. Disponível em: $<$ http://mtc-m12.sid.inpe. br/col/sid.inpe.br/sergio/2004/10.07.14.53/doc/cap2eventos.pdf.> Acesso em: 20 de março de 2013.

CARVALHO, R. M. de; NASCIMENTO, L. F. C. Spatial distribution of dengue in the city of Cruzeiro, São Paulo State, Brazil: use of geoprocessing tools. Revista do Instituto de Medicina Tropical de São Paulo, v. 54, n. 5, p. 261-266, 2012. DOI: http://dx.doi. org/10.1590/S0036-46652012000500005 
CHEN, W. J.; CHEN, L. J.; CHEN, C. C.; KING, C. C.; HARN, M. R. Silent transmission of dengue virus en Southern Taiwan. American Journal of Tropical Medicine and Hygiene, v. 55, n. 1, p. 12-26, 1996.

FLAUZINO, R.F.; SOUZA-SANTOS, R.; BARCELLOS, C.; GRACIE, R.; MAGALHÃES, M.; OLIVEIRA, R.M. Heterogeneidade espacial da dengue em estudos locais. Revista de Saúde Pública, v.43, n.6, p.1035-1043, 2009. DOI: http://arca.icict. fiocruz.br/handle/icict $/ 854$

GÓMEZ-DANTÉS, H.; RAMOS-BONIFAZ. B.; TAPIA-CONYER, M. C. El riesgo de transmisión del dengue: un espacio para la estratificación. Salud Pública de México, v. 37, n. 1, p. 88-97, 1995.

HASSAN, H.; SHOHAIMI, S.; HASHIM, N. R. Risk mapping of dengue in Selangor and Kuala Lumpur, Malaysia. Geospatial Health, v.7, n.1, p.21-25, 2012.

INSTITUTO NACIONAL DE METEOROLOGIA INMET. Banco de Dados Meteorológicos para Ensino e Pesquisa. Disponível em: <http://www.inmet.gov.br/ portal/index.php?r=bdmep.> Acesso em: 04/02/2015.

KHORMI, H. M.; KUMAR, L. Assessing the risk for dengue fever based on socioeconomic and environmental variables in a geographical information system environment. Geospatial Health, v. 6, n. 2, p. 171-176, 2012.

KHORMI, H. M.; KUMAR, L.; ELZAHRANY, R.A. Modeling spatio-temporal risk changes in the incidence of dengue fever in Saudi Arabia: a geographical information system case study. Geospatial Health, v.6, n.1, p.77-84, 2011. DOI: http://dx.doi.org/10.4081/ gh.2011.159

MENA, N.; TROYO, A.; BONILLA-CARRIÓN, R.; CALDERÓN-ARGUEDAS, Ó. Factores asociados con la incidencia de dengue en Costa Rica. Revista Panamericana de Salud Publica, v.29, n.4, p.234242, 2011. DOI: http://dx.doi.org/10.1590/S102049892011000400004
MINISTÉRIO DA SAÚDE. Fundação Nacional de Saúde. Programa Nacional de Controle da Dengue. Brasília (DF), 2002.

MONDINI, A.; CHIARAVALLOTI NETO, F.; GALLO Y SANCHES, M.; LOPES, J. C. Análise espacial da transmissão de dengue em cidade de porte médio do interior paulista Spatial analysis of dengue transmission in a medium-sized city in Brazil. Revista de Saúde Pública, v.39, n.3, p.444451, 2005. DOI: http://dx.doi.org/10.1590/S003489102005000300016

SILVA, R. M.; SILVA, L. P.; MONTENEGRO, S. M. G. L.; SANTOS, C. A. G. Análise da variabilidade espaço-temporal e identificação do padrão da precipitação na bacia do rio Tapacurá, Pernambuco. Sociedade \& Natureza, v.22, n.4, p.357-372, 2010.

SILVA, R. M.; PINTO, H. R. F.; COSTA, S. G. F.; PINTO, K. R. F. Modelagem geoespacial e temporal da hanseníase entre 2001 e 2011 no município de Bayeux, Paraíba. Hygeia, v.8, n.15, p.89-103, 2012a.

SILVA, R. M.; PINTO, H. R. F.; COSTA, S. G. F.; PINTO, K. R. F. Análise espacial da endemia hansênica no município de Bayeux (PB) mediante técnicas de SIG. Sociedade \& Natureza, v.24, n.2, p.345-358, 2012b.

TIPAYAMONGKHOLGUL, M.; LISAKULRUK, L. Socio-geographical factors in vulnerability to dengue in Thai villages: a spatial regression analysis. Geospatial Health, v.5, n.2, p.191-198, 2011. DOI: http://dx.doi.org/10.1.1.228.2803 